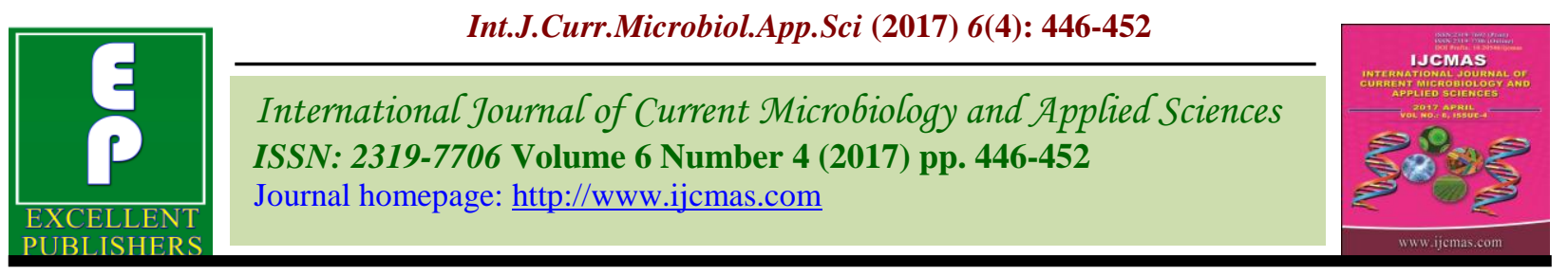

Review Article

https://doi.org/10.20546/ijcmas.2017.604.051

\title{
Rhizosphere Management Strategies for Enhance Phosphorus Utilization by Crops: An Overview
}

\author{
Anil Kumar Verma ${ }^{1}$, Brijesh Yadav², Chiranjeev Kumawat ${ }^{1}$, \\ Poonam Yadav ${ }^{3}$ and R.K. Yadav ${ }^{1}$
}

\author{
${ }^{1}$ Division of Soil Science and Agricultural Chemistry, Indian Agricultural Research Institute, \\ New Delhi - 110012, India \\ ${ }^{2}$ Division of Agricultural Physics, Indian Agricultural Research Institute, \\ New Delhi - 110012, India \\ ${ }^{3}$ SKN College of Agriculture, Jobner, Rajasthan -303029, India \\ *Corresponding author
}

\author{
A B S T R A C T
}

Keywords

Rhizosphere,

Exudates, Root morphology, PGPR, Siderophores and Mycorrhiza.

Article Info

Accepted:

02 March 2017

Available Online:

10 April 2017
Phosphorus is a major limiting factor for plant growth particularly in the tropics and subtropics areas. It play an important role in many biochemical process viz., energy storage and transfer, cell division, cell enlargement and several other processes in plants. The availability of $\mathrm{P}$ to plants is a problem owing to its slow diffusion and high fixation in soils. Due to low solubility and mobility in soil, phosphorus use efficiency is very low ranges from 10-20\% in normal soil. On the other hand, due to expansive nature and larger gap between production and consumption its use is restricted by farmers. Phosphorus efficient plants could not meet the need for $\mathrm{P}$ fertilizer hence, they are not a sustainable solution for such problems. Thus, phosphorus utilization efficiency can be improved by using certain management practices. Among these practice, rhizospheric management strategies is one of most important technique to increase P use efficiency by manipulating root growth and rhizosphere processes. This management strategies concerns mainly with manipulation in root system, microbial activity, rhizo environment and cropping system which can improves the efficient utilization of $\mathrm{P}$ in natural environment.

\section{Introduction}

Phosphorus is a major limiting factor for plant growth especially in the tropics and subtropics areas. It is one of the key components of biomolecules such as nucleic acids, phospholipids and ATP. It plays a role in energy transfer via adenosine triphosphate (ATP) and constituent of ribonucleic acid (RNA), deoxyribonucleic acid (DNA) and membrane phospholipids. Phosphorus is also involved in various enzyme reactions, cell division, cell enlargement and transformation of sugars and starch. The $\mathrm{P}$ availability to plants is a problem owing to its slow diffusion and high fixation in soils. It is fixed to a larger extent in highly weathered soil, alkaline soil and calcareous soil. It may undergo different losses by soil erosion, surface runoff and drainage. Due to low solubility and mobility in soil, phosphorus use efficiency is very low ranges from $10-20 \%$ in normal soil. On the other hand, due to expansive nature and larger gap between production and consumption its 
use is restricted by farmers. Hence, there is a clear need to grow such type of farming systems that can produce more yields with limited P availability (Lynch, 2007).

Phosphorus efficient plants are not a sustainable solution for such problems because they could not meet the need for $\mathrm{P}$ fertilizer inputs (Sanchez, 2010). Thus, phosphorus utilization efficiency can be improves by using certain management practices. Among these practice, rhizospheric management strategies is one of most important technique to increase $P$ use efficiency by manipulating root growth and rhizosphere processes. Rhizosphere is the key zone for interaction among plant roots, soil and microorganism and mainly responsible for nutrients absorption by plant roots. It as the narrow zone of soil surrounding the roots where microbial populations are stimulated by root activities and rhizosphere is directly influenced by root secretions and associated soil microorganisms. Therefore, plant root growth and various rhizosphere processes have a significant influence on nutrient transformation, mobilization, immobilization and efficient utilization by plants and thus strongly influence the crop production and sustainability (Zhang et al., 2010). Management strategies for rhizosphere includes manipulation in root system, microbial activity, rhizo environment and cropping system which can improves the efficient utilization of $\mathrm{P}$ in natural environment.

\section{Modifications in root system}

\section{Manipulation in root morphology}

The alteration of the root-to-shoot growth ratio is a general adaptive response of plants to changes in nutrient availability. Root morphology such as root length, root diameter, surface area, volume, abundance of root hairs and length of root hairs have significant influence on inter- and intraspecific variation in $\mathrm{P}$ uptake. Larger root systems provides a greater root-soil contact and absorptive areas for uptake of relatively immobile nutrients like P. Crop genotype with an extensive root systems would be efficiently utilize the $\mathrm{P}$ under starvation condition. The topsoil has higher $\mathrm{P}$ availability as compare to subsoil owing to deposition of plant litter and fertilizer residues with time. In such environments, roots traits that increase the topsoil foraging will able to acquire more $\mathrm{P}$. Researchers have been found that shallower root growth system bearing more and longer lateral roots as well as denser root hairs, increase the topsoil foraging and ultimately $\mathrm{P}$ availability. But, this trait may not be able to acquire $\mathrm{P}$ under drought condition. In Arabidopsis thaliana root architecture play a major role with a reduced number of lateral roots when $\mathrm{P}$ is limiting nutrient in both pot and field experiment (Fitter et al., 2002). In the absence of mycorrhizal association, some plants can form dense clusters of lateral roots called as 'cluster roots'. Different families viz.. Proteaceae, Fabaceae, Casuarinaceae and Myricaceae can form such type of cluster (Fig. 1).

\section{Manipulation in root physiology}

\section{Organic acid exudations}

Organic acids which are leaking from plant root, show a chelating ability to bound with phosphate and subsequently mobilize the phosphate. It have been reported that plants like Brassica napus release organic acids like malate and citrate under $\mathrm{P}$ deficiency (Hoffland et al., 1992). Zhang et al., (1997) also confirmed that under $\mathrm{P}$ deficiency condition radish release various acids such as succinic acid, malic acid and tartaric acid. Gaume et al., (2000) also reported that maize release mono- (acetic, formic, glycolic and lactic), di- (malic, oxalic and succinic) and tri(citric and trans-aconitic) carboxylic organic 
acids under $\mathrm{P}$ stress condition. Different acids produced by plant roots under various environments are given in table 1 .

\section{Enzyme exudates}

Various enzymes viz., acid phosphatases and phytases are released by plant roots into rhizosphere. Inositol phosphate and phytate constitutes up to $50 \%$ of total organic phosphorus. Their abundance in soils seems to be associated with low solublility. They can hydrolyze by various enzymes and release inorganic $\mathrm{P}$ into soil which easily taken up by plant roots. It is reported that acid phosphatases enzymes are more abundant in the rhizosphere under P starvation conditions. Hence, manipulation in enzymes activity is an alternative way to improve $\mathrm{P}$ acquisition efficiency for its subsequent utilization by plant.

\section{Microbial manipulation}

\section{Plant growth promoting rhizobacteria (PGPR)}

Plant growth-promoting rhizobacteria (PGPR) are group of bacteria that can actively colonize on plant roots and enhance nutrients availability. PGPR belongs to several genera such as Agrobacterium, Arthrobacter, Bacillus, Pseudomonas, Xanthomonas, Rhizobium, Azotobacter etc. PGPR can enhance the nutrient availability to host plants by following ways- (1) increasing the solubility of nutrients within the rhizosphere, (2) providing large surface area (3) siderophore productions (4) Production of antibiotics (5) substrate competition (6) inhibiting the growth of plant pathogens.

\section{Phosphorus solubilizing micro-organisms}

Phosphate solubilizing microorganism (PSM) are a group of heterotropic microorganism which have ability to solubilise inorganic $\mathrm{P}$ within the rhizosphere.

Phosphate solubilization ability of PSM is considered as one of the most important traits with respect to phosphate nutrition. It is widely accepted that the mechanism of phosphate solubilization by PSM is mainly associated with the release of various low molecular weight organic acid (Table 2). These acids have different carboxyl and hydroxyl groups which bound the phosphate and convert it into plant available forms.

\section{Mycorrhizae}

The symbiotic association between plant roots and fungi is known as mycorrhizal association which improves the growth and yield of crops in nutrient deficient conditions. These are obligates symbiont within the rhizosphere with a network of hyphae and extensive growth.

They play a vital role in efficient use of Pfertilizer. This association is very effective under agroforestry system. Mycorrhizal roots can take up several times more P per unit root length than non mycorrhizal roots.

\section{Siderophores}

Siderophores are released by microbes under nutrient deficient conditions specifically $\mathrm{Fe}$ stress condition (Cabaj and Kosakowska, 2009). Gierer et al., (1992) reported that Vibrio anguillarum, Aeromonas spp. and Pseudomonas spp. could produce hydroxamate or catecholate-type siderophores. However, siderophore production is not widely accepted as $\mathrm{P}$ solubilising mechanism. Some researcher confirmed that hydroxamate siderophores could effectively increase the phosphorus uptake by solubilization of phosphorus from iron phosphates at acid $\mathrm{pH}$. 
Table.1 Organic acids produced by plant roots

\begin{tabular}{|l|l|l|}
\hline \multicolumn{1}{|c|}{ Plant species } & \multicolumn{1}{|c|}{$\begin{array}{c}\text { Organic acid released } \\
\text { (Dominant) }\end{array}$} & \multicolumn{1}{c|}{ References } \\
\hline White lupin, Alfalfa & Citric acid & (Watt and Evans, 1999) \\
\hline Maize, Wheat, Oilseed rape, Tomato & Malic acid & (Neumann and Romheld, 2006) \\
\hline Sugar beet & Oxalic acid & (Gerke et al., 2000) \\
\hline
\end{tabular}

Table.2 Phosphorus solubilizing micro-organisms

\begin{tabular}{|c|c|c|}
\hline P solubilizers & Predominant Acids & References \\
\hline \multicolumn{3}{|c|}{ Phosphate solubilizing bacteria } \\
\hline Enterobacter intermedium & 2-ketogluconic & Hoon et al., 2003 \\
\hline Pseudomonas striata & Malic, glyoxalic, succinic, & Gaur, 1990 \\
\hline Pseudomonas cepacia & Gluconic, 2-ketgluconic & Bar-Yosef et al., 1999 \\
\hline Bacillus polymyxa,, Bacillus spp. & Oxalic, citric & Gupta et al., 1994 \\
\hline Arthrobacter sp. & Oxalic, malonic & Banik and Dey, 1982 \\
\hline Micrococcus spp. & Oxalic & Banik and Dey, 1982 \\
\hline \multicolumn{3}{|l|}{ Phosphate solubilizing Fungi } \\
\hline $\begin{array}{l}\text { Aspergillus flavus, } A \text {. niger, } A \text {. } \\
\text { awamori, A.foetidus, }\end{array}$ & Oxalic, citric, gluconic succinic & Maliha et al., 2004 \\
\hline Penicillium sp. & Oxalic, itaconic & Parks et al., 1990 \\
\hline Chaetomium nigricoler & Oxalic, succinic, citric, 2-ketogluconic & Banik and Dey, 1983 \\
\hline \multicolumn{3}{|c|}{ Phosphate solubilizing actinomycetes } \\
\hline Streptomyces & Lactic, 2-ketogluconic & Banik and Dey, 1982 \\
\hline Scwaniomyces occidentalis & $\begin{array}{l}\text { Succinic, fumaric, citric, tartaric, } \alpha- \\
\text { ketbutyric }\end{array}$ & Gaur, 1990 \\
\hline
\end{tabular}

Fig.1 Different rhizosphere management strategies for enhance P utilization

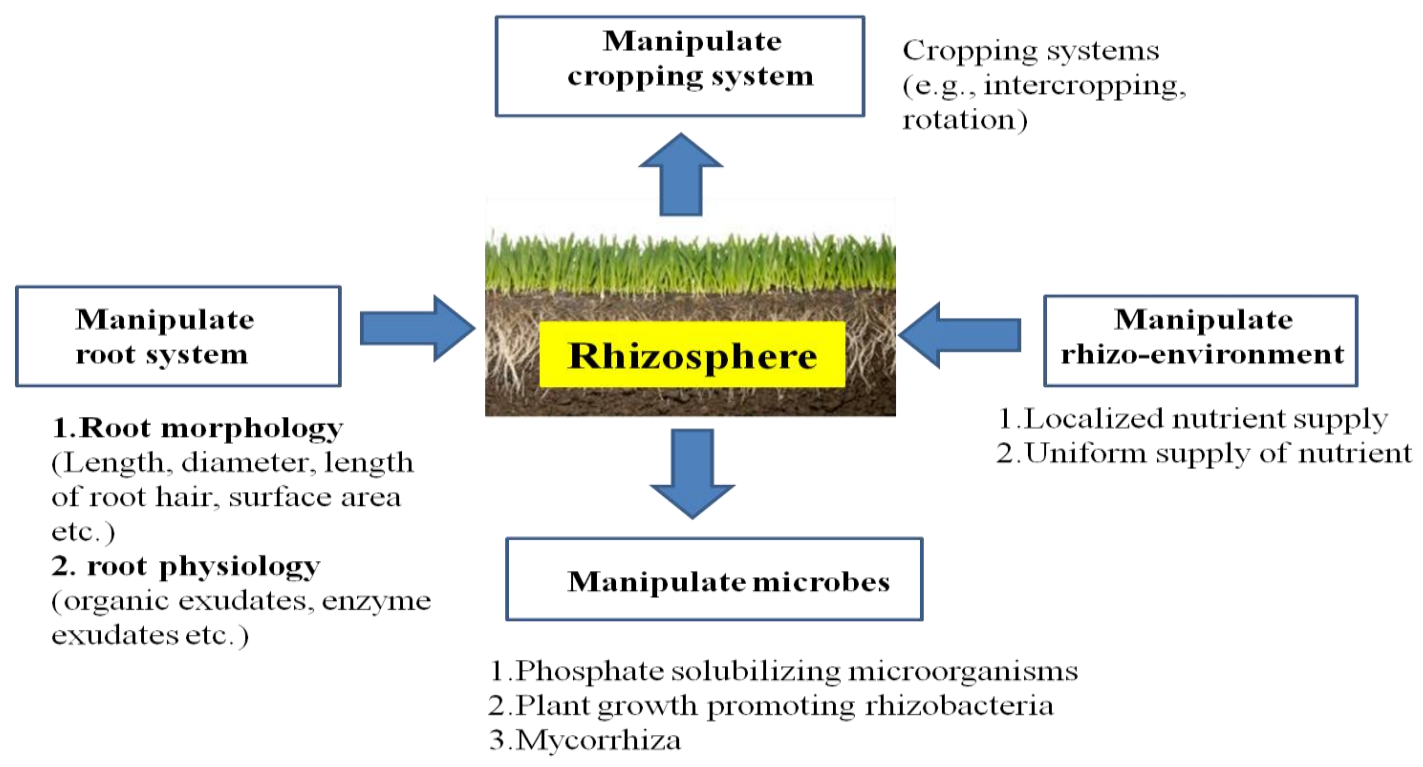




\section{Manipulation in rhizo-environment}

Site specific nutrient management with synchronize application of nutrient is important for maximizing the $\mathrm{P}$ use efficiency. This can be achieve by manipulate the rhizo-environment through optimum nutrient supply, uniform nutrient application and localized application of nutrient.

\section{Uniform and optimize nutrients supply}

Overuse of fertilizer may cause high concentration of nutrients in the rhizosphere which may leads to inhibition of root growth and various rhizosphere processes resulting affect $\mathrm{P}$ mobilization (Li et al., 2008 and Shen et al., 2011). The dissimilar nutrient concentrations in soil have an significant influence on plant nutritional status and produce a response from aboveground to belowground to adjust the rhizosphere environment (Zhang et al., 2010). It is found that excess application of nutrient enhances the nutrient concentration in solution which hampers the $\mathrm{P}$ mobilization and uptake by crops. Hence, regulation of nutrient supply intensity to a optimum level might be helpful to enhance $\mathrm{P}$ use efficiency.

\section{Localized application of nutrients}

Plants take nutrients mostly through the rhizosphere which is a key zone of interaction among soil, microbes and roots. Many studies shows that localized application of ammonium coupled with superphosphate significantly increases the crop growth in calcareous soil because ammonium absorption promotes release of protons by roots and reduces the rhizosphere $\mathrm{pH}$ which finally increases the $\mathrm{P}$ availability (Jing et al., 2012).

Thus, modifying rhizosphere processes by manipulating the supply intensity and localized nutrient supply may be an effective management strategy for increasing nutrient use efficiency.

\section{Rhizosphere interactions between intercropped legumes and cereals}

Legumes-cereals intercropping system is widely followed in many region of countries. Li et al., (2007) found that $\mathrm{P}$ can be mobilized by legume plants because legumes can decrease the rhizosphere $\mathrm{pH}$ through release of proton in a $\mathrm{P}$ deficient intercropping system. He reported that reduction in rhizosphere $\mathrm{pH}$ i.e. from 6.5 to 4.1 may cause improvement in $\mathrm{P}$ nutrition in faba beanmaize intercropping system. Chickpea can improve $\mathrm{P}$ nutrition of wheat through enhancing the phosphatase activity (Li et al., 2004).

\section{References}

Banik, S. and Dey, B.K. 1982. Available phosphate content of an alluvial soil as influenced by inoculation of some isolated phosphate-solubilizing microorganisms. Plant and Soil, 69(3): 353364.

Banik, S. and Dey, B.K. 1983. Phosphatesolubilizing potentiality of the microorganisms capable of utilizing aluminium phosphate as a sole phosphate source. Zentralblatt fuer Mikrobiologie, 138(1): 17-23.

Bar-Yosef, B., Rogers, R.D., Wolfram, J.H. and Richman, E. 1999. Mediated Rock Phosphate Solubilization in Kaolinite and Montmorillonite Suspensions. Soil Sci. Soc. America J., 63(6): 1703-1708.

Cabaj, A. and Kosakowska, A. 2009. Irondependent growth of and siderophore production by two heterotrophic bacteria isolated from brackish water of the southern Baltic Sea. Microbiol. Res., 164(5): 570-577. 
Duncan, W.G. and Ohlrogge, A.J. 1959. Principles of nutrient uptake from fertilizer bands: III. Band volume, concentration, and nutrient composition. Agron. J., 51(2): 103-106.

Fitter, A., Williamson, L., Linkohr, B. and Leyser, O. 2002. Root system architecture determines fitness in an Arabidopsis mutant in competition for immobile phosphate ions but not for nitrate ions. Proceedings of the Royal Society of London B: Biological Sciences, 269(1504): 2017-2022.

Gaume, A., Weidler, P.G. and Frossard, E. 2000. Effect of maize root mucilage on phosphate adsorption and exchangeability on a synthetic ferrihydrite. Biol. Fertility of Soils, 31(6): 525-532.

Gaur, A.C. 1990. Phosphate solubilizing micro-organisms as biofertilizer. Omega scientific publishers.

Gerke, J., Beißner, L. and Römer, W. 2000. The quantitative effect of chemical phosphate mobilization by carboxylate anions on $\mathrm{P}$ uptake by a single root. I. The basic concept and determination of soil parameters. J. Plant Nutrition and Soil Sci., 163(2): 207-212.

Gierer, W., Rabsch, W. and Reissbrodt, R. 1992. Siderophore pattern of fish-pathogenic Vibrio anguiliarum, Aeromonas spp. and Pseudomonas spp. from the German Baltic coast. J. Fish Dis., 15(5): 417-423.

Gupta, R., Singal, R., Shankar, A., Kuhad, R. C. and Saxena, R.K. 1994. A modified plate assay for screening phosphate solubilizing microorganisms. J. General and Appl. Microbiol., 40(3): 255-260.

Hoffland, E. 1992. Quantitative evaluation of the role of organic acid exudation in the mobilization of rock phosphate by rape. Plant and Soil, 140(2): 279-289.

Hwangbo, H., Park, R.D., Kim, Y.W., Rim, Y.S., Park, K.H., Kim, T.H., Kim, K.Y.
2003. 2-Ketogluconic acid production and phosphate solubilization by Enterobacter intermedium. Curr. Microbiol., 47(2): 0087-0092.

Jing, J., Zhang, F., Rengel, Z. and Shen, J. 2012. Localized fertilization with $P$ plus $\mathrm{N}$ elicits an ammonium-dependent enhancement of maize root growth and nutrient uptake. Field Crops Res., 133: 176-185.

Li, H., Shen, J., Zhang, F., Tang, C. and Lambers, H. 2008. Is there a critical level of shoot phosphorus concentration for cluster-root formation in Lupinus albus?. Functional Plant Biol., 35(4): 328-336.

Li, L., Li, S.M., Sun, J.H., Zhou, L.L., Bao, X.G., Zhang, H.G. and Zhang, F.S. 2007. Diversity enhances agricultural productivity via rhizosphere phosphorus facilitation on phosphorus-deficient soils. Proceedings of the National Academy of Sciences, 104(27): 1119211196.

Li, S.M., Li, L., Zhang, F.S. and Tang, C. 2004. Acid phosphatase role in chickpea/maize intercropping. Annals of Botany, 94(2): 297-303.

Lynch, J.P. 2007. Roots of the second green revolution. Australian J. Botany, 55(5): 493-512.

Neumann, G. and Römheld, V. 2007. The release of root exudates as affected by the plant physiological status. In The Rhizosphere: Biochemistry and Organic Substances at the Soil-Plant Interface, Second Edition (pp. 23-72). CRC Press.

Parks, E.J., Olson, G.J., Brinckman, F.E. and Baldi, F. 1990. Characterization by high performance liquid chromatography (HPLC) of the solubilization of phosphorus in iron ore by a fungus. $J$. Industrial Microbiol., 5(2-3): 183-189.

Rashid, M., Khalil, S., Ayub, N., Alam, S. and Latif, F. 2004. Organic acids production and phosphate solubilization 
by phosphate solubilizing microorganisms (PSM) under in vitro conditions. Pak. J. Biol. Sci., 7(2): 187196.

Sanchez, P.A. 2010. Tripling crop yields in tropical Africa. Nature Geosci., 3(5): 299-300.

Shen, J., Li, C., Mi, G., Li, L., Yuan, L., Jiang, R. and Zhang, F. 2012. Maximizing root/ rhizosphere efficiency to improve crop productivity and nutrient use efficiency in intensive agriculture of China. J. Experimental Bot., ers342.
Watt, M., Evans, J.R. 1999. Linking development and determinacy with organic acid efflux from proteoid roots of white lupin grown with low phosphorus and ambient or elevated atmospheric $\mathrm{CO}_{2}$ concentration. Plant Physiol., 120: 705-716.

Zhang, F., Shen, J., Zhang, J., Zuo, Y., Li, L. and Chen, X. 2010. Chapter onerhizosphere processes and management for improving nutrient use efficiency and crop productivity: implications for China. Adv. Agron., 107: 1-32.

\section{How to cite this article:}

Brijesh Yadav, Anil Kumar Verma, Chiranjeev Kumawat and Poonam Yadav. 2017. Rhizosphere Management Strategies for Enhance Phosphorus Utilization by Crops: An Overview. Int.J.Curr.Microbiol.App.Sci. 6(4): 446-452. doi: https://doi.org/10.20546/ijcmas.2017.604.051 